\title{
Psychosocial Programmes and Employees Retirement Preparedness: Empirical Evidence From the Educational Sector in Kenya
}

\author{
Titus G. Gathiira ${ }^{1}$, Stephen M.A. Muathe ${ }^{2} \&$ James M. Kilika $^{2}$ \\ ${ }^{1}$ Karatina University, Kenya \\ ${ }^{2}$ Department of Business Administration, Kenyatta University, Nairobi, Kenya \\ Correspondence: James M. Kilika, Department of Business Administration, Kenyatta University, Nairobi, Kenya. \\ Received: January 4, 2019 \\ doi:10.5430/ijba.v10n2p82
}

\begin{abstract}
Retirement is a process with employees planning decisions generally focusing on the subjective life expectancy, a mental model of years remaining before one dies. Indeed, the real exit of an individual from a career job is accompanied by changes that include social and psychological, resources leading to variations in an individual's well-being. The purpose of this study was to assess how employees' engagement in psychosocial programmes affects their retirement preparedness in the education sector in Kenya. The target population was 1,238 teachers aged 50 years and above and employed in public secondary schools by the Teachers Service Commission in Kirinyaga and Murang'a Counties by 2017. A representative sample of 334 respondents was selected using multistage sampling technique. Data was collected using semi structured questionnaire and interview guide. Logit regression was used to establish the relationships between variables in the study and to test the null hypotheses at $\mathrm{P} \leq 0.05$ confidence level. The findings indicate that even though the sampled pre-retiree teachers were not adequately prepared for retirement psychosocially, yet their engagement in psychosocial programmes increases their retirement preparedness level. The reported findings extend the current understanding of employee separation programmes and raise implications for the various theories that underpin employee separation decisions in HRM.
\end{abstract}

Keywords: psychosocial programmes, retirement preparedness, retirement, teachers

\section{Introduction}

The construct of Retirement has been conceptualized to reflect its dynamic nature that demonstrates potential for response to external forces (August, 2011) since its evolution is molded by social-economic factors (Davies \& Jenkins, 2013). The retirement dynamics illuminate the strategies employed by individual employees to maintain, negotiate or re-invent themselves during retirement (McVittie \& Goodall, 2012). Contemporary retirement has been affected by the nature of work that requires less physical effort, increased life longevity and the adoption of pro-work practices as opposed to leisure retirement (Feldman \& Beehr, 2011). Increased life longevity implies that a typical adult may expect to live 20-30 years in retirement (WHO, 2012). Inadequate retirement preparation prompts separation from employer organization to trigger a decline in life satisfaction and quality of life resulting to various negative economic, social, psychological and physiological consequences (Wang \& Hesketh, 2012). Therefore, employee retirement planning should not be a concern only during the second half of employee's life, but rather from start of employment (Ekerdt, 2004; Phua \& McNally, 2008). Effective retirement planning programmes should enhance psychosocial resources of an individual resulting to improved adaptation in retirement transition (Shultz \& Wang, 2007; Chan, Gustafsson \& Liddle, 2015).

Proponents of life course perspective deduce that, individuals who are less socially integrated with their work and the employer exhibit attributes that help in smoothening retirement transition, show better preparedness for the retirement adjustment and achieve better retirement outcomes (Wang \& Shultz, 2010). In addition, theorists have it that, employees with perceived control over the separation from the workforce demonstrate better retirement adjustment (van Solinge \& Henkens, 2008). The life course theory considers how aging relates to and is shaped by social contexts, history, time period, cultural meanings and location (Hooyman \& Kiyak, 2000). It further explains that successful retirement transition is pre-retirees' context dependent that includes social context such as social networking and family structure (Elder \& Johnson, 2003; Mariappanadar, 2012). Life course perspective therefore provides a useful framework for examining the dynamic and complex nature of the retirement transition and 
adjustment process by viewing the retirement transition as one where individual, contextual and psychological factors interact (Donaldson, Earl, \& Muratore 2010). From the foregoing, life course perspective was considered appropriate to anchor the current study.

In line with role theory, being retired can be characterized as a role transition that includes processes of losing or weakening work roles such as the worker role, the organizational member role, and the career role and strengthening the family member role and the community member role (Wang, Henkens \& Van Solinge, 2011). Role theorists argue that loss of a fundamental role resulting from retirement transition can cause individuals to feel stressed, anxious and depressed, which may lead to low levels of well-being in retirement (Quick \& Moen, 1998; Kim \& Moen, 2001). Although one's life after retirement might be viewed as less satisfying than the years when one was employed, some retirees with other role involvements or those who retire from unpleasant jobs may be less troubled or even more pleased with the loss of those work roles (Wang et al., 2011). On the other hand, role theory indicates that individuals who engage more fully in the roles of family and community members view retirement as an opportunity for them to get time to enjoy the rewards and responsibilities tied to those roles (Ibid, 2011). Further, bridge employment can be characterized as a role transition from full-time work to retirement (Mariappanadar, 2012). Therefore, role theory places specific focus on the role changes that occur through leaving the workforce and the need to create new roles to replace those lost.

\subsection{Statement of the Problem}

Globally, there is increased life expectancy with people aged 60 and above expected to almost triple in the next 45 years (Valero \& Topa, 2014). In developed countries, one-fifth of the populace is aged 60 or older and it is expected to rise to almost one-third by 2050 . Similarly, in developing countries older population is expected to rise from $10 \%$ to 20\% between 2005 and 2050 (August, 2011). Research demonstrates that in Asia and Australia, the current 13\% population aged over 65 years will increase to $26 \%$ by 2050 (Pillay, Kelly \& Tones, 2010) and this trend of increasing number of pre-retirees is similar to other countries like Japan, UK and USA among others (Wang \& Shultz, 2010). In many countries and regions of the world such as USA, Europe, Asia, and sub-Saharan Africa, teachers remain inadequate especially at secondary level and the situation is bound to worsen due to many of the teachers likely to retire in the coming decade (UNESCO, 2007). In France nearly $30 \%$ of teaching profession is over 50 years against mandatory retirement age of 60 , with a third of all teachers expected to leave the profession within the next five years. Of greater concern is Germany where $70 \%$ will retire within the next 15 years and over $60 \%$ in England all school leaders are expected to retire during the coming decade (UNESCO, 2007). The ageing population is not the problem in itself, but the demographic changes which generate an increase in pre-retirees based on mandatory retirement age whose retirement preparedness is a function of psychosocial programmes initiated.

Pre-retirees are affected by disengagement processes and mental withdrawal from their jobs years before actual retirement as they mourn eventual major disruptions that include loss of social identity, friendship and social exclusion (Beehr \& Bennett, 2007). The social fabric dynamics render over reliance on the traditional forms of old age support such as extended family, community, social culture and even taboos to be no longer tenable (Okoth \& Anami, 2012). Therefore, as part of retirement preparation, employees engage into different programmes or activities as part of retirement planning (with very few opting for the traditional full leisure retirement) in order to continue keeping social and psychological connections (Shultz \& Henkens, 2010). Additionally, most of the researches conducted on retirement preparedness were carried out in western countries (Wang \& Shultz, 2010) and on retirees (Donaldson, Earl, \& Muratore, 2010) and in sectors of the economy such as construction, infrastructure, manufacturing, maintenance, and quarrying (Mariappanadar, 2012) leaving the situation in the education sector more less unexplained. Majority of studies that have attempted to focus on educational sector have examined retired academic staff (Dorfman, 2009) while a study on pre-retiree employees in educational sector on attitudes and experiences of work to retirement transition had university staff as respondents (Davies \& Jenkins, 2013). Fewer studies have been conducted on the perceptions and attitudes of academic staff in the process of experiencing retirement transition (Thody, 2011). The authors sought to address this logical gap by providing empirical data on the effects of psychosocial programmes on pre-retiree retirement preparedness in the educational sector, specifically in secondary schools.

The purpose of this study was to assess how employees' engagement in psychosocial programmes affects their retirement preparedness in the education sector in Kenya. The specific objectives of the study were to assess the effect of social embeddedness, retirement counseling and mentorship opportunities on retirement preparedness among public secondary school teachers in two Counties in Kenya.

The study is significant because it contributes towards filling the knowledge gap towards the unresolved academic 
arguments concerning the nexus between psychosocial aspects of employee separation as a construct in human resource management and retirement preparedness (Wang \& Shultz, 2010). The extant literature indicates that separation aspects of human resource management are ignored in theory and even the little attempts by authors like Armstrong (2006) have inherent weaknesses. Past studies examining retirement preparation adequacy mainly focus on financial preparedness (Dalirazar, Vornovytskyy, \& Hedengren, 2010; Muratore \& Earl, 2010; Feldman \& Beehr, 2011; Shultz \& Wang, 2011) hence neglecting the psychological and social dimension of retirement preparedness. The study therefore provides empirical evidence as the basis of formulating a model to explain the employee retirement planning using psychosocial programmes as a parameter that determines retirement preparedness. In addition, the study is conducted in a sector of the economy that employs the highest number of employees (i.e 288,000, according to UNESCO, 2015) and is considered to be one of the pillars of national development. More so, it is expected for pre-retirees who perceive themselves inadequately in retirement preparedness to result to poor service delivery as they disengage from commitment to work roles and ultimately the economy suffers. In undertaking the study, the authors contribute towards effective management of employees in the education sector for better service delivery given the psychological expectations on each to demonstrate unique competencies which may adversely be affected by psychological tensions brought about by the advent of retirement.

\section{Literature}

\subsection{Theoretical Review}

In view of the extant state of the conceptual and theoretical literature on separation as an important function in HRM, that to a great extent has affected the practice, it becomes imperative to address this state by anchoring separation decisions in the appropriate theoretical underpinnings. In this study, the authors identify three theories rooted in the behavioural sciences to enhance the understanding of the construct of separation and more specifically, on the psychological and sociological aspect of employees that are of relevance to HRM practice. The study therefore is anchored in role theory, continuity theory and the theory of planned behaviour.

Role theory views retirement as an adjustment of one's principal role as a paid employee that is central to an individual's identity (Kim \& Moen, 2001) and emphasizes the importance of the role exit and the role transition in retirement adjustment (Wang, Henkens \& van Solinge, 2011). Being retired therefore can be characterized as a role transition that includes processes of losing or weakening work roles such as the worker role, the organizational member role, and the career role and strengthening the family member role and the community member role (Wang et al., 2011). It is therefore imperative for an employee to deliberately plan and engage in specific programmes that socially and psychologically exhibit the new roles of an individual after separation from the employer organization. Since the extent to which an individual is highly invested in a given role influences feelings of self-worth (Ashforth, 2001), the new roles after retirement should give retirees an equivalent sense of worth and achievement as when employed (Choi, 2001) and assist shaping behaviour and self-concept (Hooyman \& Kiyak, 2000). Role theory therefore places specific focus on the role changes that occur through leaving employer organization and the need to create new roles to replace those lost through well thought out psychosocial programmes.

The theoretical underpinnings are further reinforced by continuity theory that emphasizes on the consistency of life patterns over time (Atchley, 1989 cited in Wang, 2007) by accommodating life changes without the experience of stressful disruption. As such, continuity theorists buttress individuals to make adaptive choices over time to preserve and maintain existing internal and external structures (Atchley, 1989; Mariappanadar, 2012). However, continuity does not refer to clinging to the past in resisting change, but adjustment and adaption to unfolding state of affairs that ensures considerable continuity in identity and self-concept over the retirement transition, resulting to individual's retirement adjustment.

Conceptualization of employees as a thoughtful engagement in psychosocial programmes in preparation for retirement makes retirement preparedness a predictable deliberate behavioural intent of people as propagated by the theory of planned behaviour (Ajzen, 1991). That is, the individual's intentions buttress motivational elements that influence performance of the psychosocial programmes. According to Wang and Shultz (2010), the general premise of this theory is that pre-retirees' attitudes toward retirement influence the activities to be involved in preparation for retirement. The theory of planned behaviour recognizes behavioural control and intention utilization to predict behavioural achievement with considerable accuracy especially when behaviours do not pose severe problems of control (Sheppard, Hartwick \& Warshaw, 1988). The planned behavioural achievement empowers the retirees in aspects of life transition endeavouring achievement of psychological comfort with their retirement life (van Solinge \& Henkens, 2008).

The study conceptualized separation (the last process in human resource management) as an aspect that necessitates 
organizational practices that influence individual employees to engage in activities (programmes) that assure successful social and psychological preparedness. The authors postulated that pre-retirees' engagement in activities that stimulate social orientation/embeddedness, mentorship opportunities and retirement counseling empowers them to be better placed after leaving the employer organization without experiencing adversity and hence welcome retirement as another stage of life.

\subsection{Conceptual and Empirical Review}

Since retirement preparedness is the outcome of a process that commences with retirement planning (Marshall, Clarke, \& Ballantyne, 2001), researchers recommend individual employees to start retirement preparation long before one leaves the workforce (Anderson, Bechhofer, McCrone, \& Stewart, 2000). However, some employees take retirement preparedness seriously (Petkoska \& Earl, 2009) while many others prepare inadequately or not at all (Ekerdt, Hackney, Kosloski, \& DeViney, 2001). There is therefore undisputable need for retirement preparedness (Topa, Moriano, Depolo, Alcover, \& Morales, 2009). Studies indicate that retirement transition is often affected by many life domains and is usually accompanied by a decline in life satisfaction, self-evaluation, and quality of life (Lusardi \& Mitchell, 2011). As Wang and Shultz (2010) put it, conceptualizing retirement preparedness as part of human resource management emphasizes the value of managing retirement to help organizations achieve their goals by promoting human resource practices that influence individual employee's retirement decisions and retirement planning. The foregoing arguments are crucial and reveal concrete and practical effects of separation planning programs in terms of psychosocial factors that require considerations by employees and employers. As a matter of fact, awareness of 'how to' and 'what to' empower employees to act promptly in retirement preparation both socially and psychologically cannot be over emphasized. The researchers postulated three variables of psychosocial programmes that predict retirement preparedness in secondary schools in Kenya; that is social embeddedness, retirement counselling and mentorship opportunities.

Studies indicate that there are critical factors that affect retirement preparedness of employees such as work content and environment, individual health, social embeddedness and the psychological processes preceding late career employment and retirement decisions (Butters, 2002; Butters, 2004; Shultz \& Henkens, 2010). A study by Hesketh, et al. (2014) reported the need to conduct sensitizations on coping with performance outcomes (other than job performance) in the work environment such as healthy behaviours, retirement planning, and successful social interaction at home and in the community. Individuals' engagement in activities such as in the local church, extended family, community by pre-retirees provides forums of social inclusion even after retirement. The findings of Beehr and Bennett (2007) showed that pre-retirees are affected by disengagement processes and mental withdrawal from their jobs years before they actually retire as they mourn the fear of social exclusion after retirement.

Findings by Shultz and Wang (2011) demonstrate that retirement counseling interventions should include assisting employees in retirement planning and decision making through development of occupational self-efficacy beliefs, postretirement work outcome expectations and occupation related activities. As suggested by Kim, Kwon and Anderson (2005), there is need to study retirement planning in terms of engagement in psychosocial programmes and their effect to retirement preparedness. Retirement counselling activities include participating in workshops and seminars, discussion with friends and family members, reading literature and listening to media programmes. The rationale is that, retirement preparedness is a function of retirement planning that requires knowledge of retirement issues on psychological wellbeing (Kim et al., 2005).

Some studies indicate that, post-retirement activities such as bridge employment and volunteer work such as mentorship of younger generation are beneficial to retirees' psychological well-being (Dorfman \& Douglas, 2005; Wang, 2007; Zhan, Wang, Liu \& Shultz, 2009). However, Wang and Hesketh (2012) found that the beneficial effects of bridge employment on retirees' psychological well-being depend on the type of bridge employment taken. This agrees with the findings of Zhan et al., (2009) that beneficial effect of post-retirement activities in promoting psychosocial wellbeing is more likely to appear among retirees who engage in career-related bridge employment rather than bridge employment in a different field. In what seems to further the argument, Dendinger, Adams and Jacobson (2005) reported that, when retirees work for generative reasons (such as working for teaching and sharing knowledge with the younger generations) they are more likely to experience improved psychological well-being.

The findings of Beehr and Bennett (2007) showed that pre-retirees are affected by disengagement processes and mental withdrawal from their jobs years before they actually retire as they mourn the fear of social exclusion after retirement. In a study by Shultz and Henkens, (2010), it was found that employees engage in some type of hybrid employment of phased retirement with very few opting for the traditional full leisure retirement in order to continue keeping social connections. Moreover, in their study on retired managers, Sargent, Bataille, Vough and Lee, (2011) 
highlighted both consumer and producer-based retirement identities. Individual employees were found to put mechanisms in place to enable them work in retirement in order to maintain their pre-retirement professional identity and to distance themselves from leisure-based consumer identities. There is therefore need to establish the psychosocial programmes that pre-retirees engage in for retirement preparedness.

Majority of the past studies examining retirement preparation adequacy mainly focused on financial preparedness (Dalirazar, Vornovytskyy, \& Hedengren, 2010; Muratore \& Earl, 2010; Feldman \& Beehr, 2011; Shultz \& Wang, 2011) thus neglecting psychological retirement preparedness. In a survey exploring psychosocial factors relationship to retirement intentions, older workers' identity was found to be positively related to full retirement intentions and negatively related to job mobility (Shultz \& Henkens, 2010). The foregoing reveal concrete and practical implications planning programs on retirement preparedness in terms of psychosocial factors that require considerations by employees and employers. As suggested by Kim, Kwon and Anderson (2005), there is need to study the relationship between the psychosocial programmes in retirement planning and retirement preparedness. The rationale is that, retirement preparedness is a function of retirement planning that requires knowledge of retirement issues on psychological wellbeing (Kim et al., 2005). Therefore, awareness of 'how to' and 'what to' empower employees to act promptly in retirement preparation both socially and psychologically is too protuberant to be neglected.

\subsection{Conceptualization and Hypotheses}

The relationship between the components of psychosocial programmes and retirement preparedness was proposed to constitute a linear relationship in which the components are the predictors while retirement preparedness is the criterion factor. The relationship is modeled in figure 1.

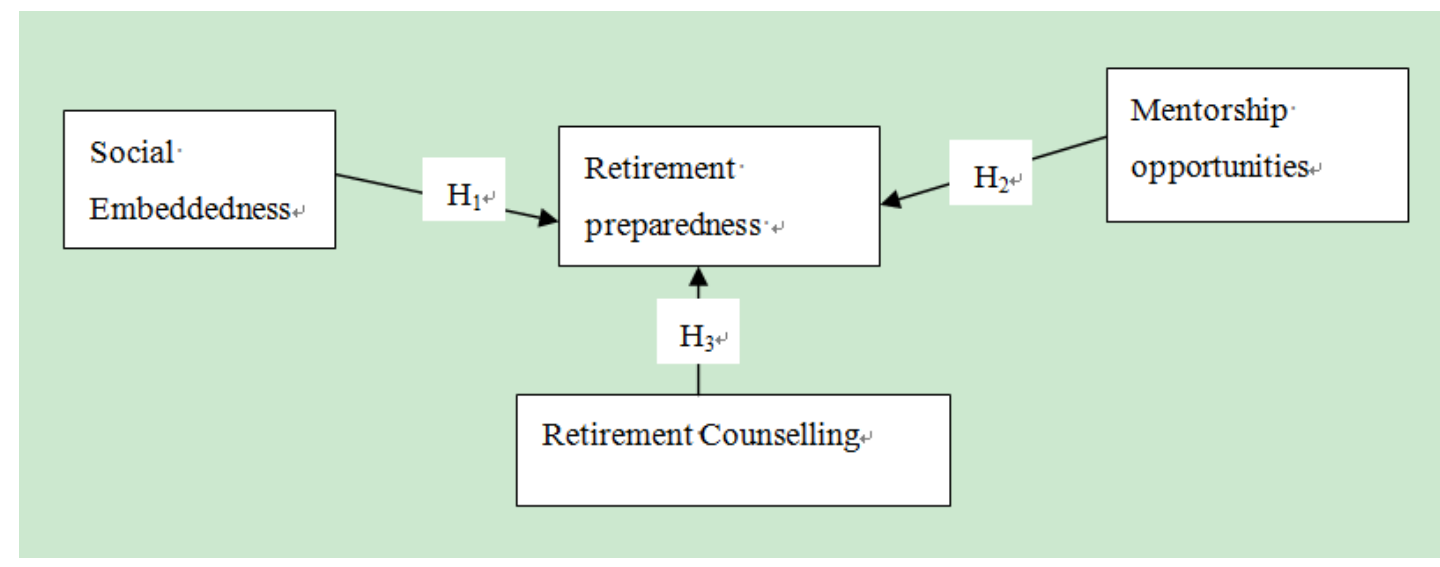

From the empirical evidence obtained from previous studies, (Noone, Stephens, \& Alpass, 2009) and the theoretical literature, we propose a positive relationship between the predictor and criterion variables of the study. In absence of any contrary finding for the educational sector in Kenya, we propose that employee engagement in psychosocial programmes will positively affect the level of their retirement preparedness. Specifically, we propose the following three hypotheses that:

$H_{1}$ There is a significant effect of employee's engagement in social orientation programmes on retirement preparedness among teachers' in secondary schools in Kenya;

$\mathrm{H}_{2}$ There is a significant effect of employee's engagement in mentorship opportunities programmes on retirement preparedness among teachers' in secondary schools in Kenya; and

$\mathrm{H}_{3}$ There is a significant effect of employee's engagement in retirement counseling programmes on retirement preparedness among teachers' in secondary schools in Kenya

\section{Methodology}

\subsection{Context of Study}

Education in Kenya is structured to comprise basic education (that covers primary and secondary education), Tertiary education and university education (MoE, 2012). For administrative purposes, administration and management of education is devolved to Counties headed by the County Directors of Education. Moreover, the day to day 
management of secondary education is by the head teachers designated as principals supported by the Boards of Management. The current study was conducted in Kirinyaga and Murang'a Counties because the two Counties had suffered great loss of life due to alcohol abuse compared to other Counties in Kenya (NACADA, 2014) and the victims included teachers. Earlier studies had opined that retirement poses significant adjustment challenges for older employees (Kim \& Moen, 2001) that include maladjustment leading to increased alcohol use (Perreira \& Sloan, 2001). This was supported by a recent study by Bamberger (2014), that retirement as a significant life change impact on older adults' drinking behavior, exacerbating prior patterns of heavy drinking or even precipitating alcohol misuse.

\subsection{Design, Target Population and Sampling}

This study employed descriptive research design. As observed by Sekaran and Bougie (2009) there is no single perfect design. This was appropriate because it provided a comprehensive and detailed explanation of the phenomena of pre-retiree teachers concerning separation planning in terms of psychosocial programmes on retirement preparedness for a conclusive research as proposed by Chawla and Sondhi (2011). The target population was 1,238 teachers employed by the Teachers Service Commission in Kirinyaga and Murang'a Counties' secondary schools who were ten years to mandatory retirement age (50 years and above) by 2017. Although the study employed Yamane (1967) formula, to yield a sample size 302 (24.39\%) of target population, the study enlarged the sample size to $334(26.98 \%)$ in order to avoid Type I error (falsely rejecting a true null hypothesis) and Type II error (wrongly accepting a false null hypothesis). According to Fox, Hunn., and Mathers (2009), studies that test hypotheses seeking to generalize the findings need to enhance the statistical significance and statistical power by enlarging the study's sample size to make allowance of non-responses.

The study adopted a multistage sampling technique which is commonly used when the population is scattered over a wide area and three or more stages of sampling applied (Chauvet, 2015). Stage one was identification of Kirinyaga and Murang'a Counties from the 47 Counties using convenience sampling due to their proximity to the researcher. Stage two was identification of the school category namely National, Extra County, County and Sub-County through proportionate stratified sampling technique. Stage three was selection of the actual respondents using purposeful sampling technique to identify Teachers Service Commission employed teachers aged 50 years and above.

\subsection{Research Data}

Data was collected using a semi-structured questionnaire. The first section identified as A contained seven items on demographic profile of the applicant while the second section, B had twenty-four items named as individual engagement in psychosocial programmes. Three sub-variables namely social orientation/embeddedness, mentorship opportunities and retirement counseling were included for the respondents to express opinions on how well they participated in activities that made them well entrenched psychosocially. For the independent variable, the items measurements were in 5-point Likert Scale as follows; strongly disagree (1), disagree (2), uncertain (3), agree (4), and strongly agree (5). To determine retirement preparedness, responses from respondents were also awarded scores using a 5-point Likert Scale namely definitely false (1), false (2), neither (3), true (4), and definitely true (5).

\subsection{Diagnostic Tests}

For this study, the collinearity tests were conducted using correlation analysis, tolerance and (VIF) analysis. The tolerance statistics was to be above 0.1 and VIF less than 10 for multicollinearity problem not be a concern (Menard, 1995; Field, 2012). The variance inflation factors VIF values was 1.422 which was far well below ten (10) while the tolerance statistics 0.703 , also far well above 0.1 . Consequently, the study concluded that there was no problem of multicollinearity. Sampling adequacy for factor analysis is tested by high values of KMO greater than 0.5 and confirmed by Bartlett's test of sphericity significant at $\mathrm{p} \leq 0.05$ (Field, 2013). After conducting the principal component analysis for all items with varimax rotation, the data sample of this study was adequate for factor analysis because KMO was 0.826 (greater than 0.5 ) while the Bartlett's test of sphericity was significant, $\mathrm{p}=0.000$, which was less than $\mathrm{p} \leq 0.05$. In order to test Goodness of fit for the model, Hosmer and Lemeshow (H-L) test was employed to determine how well the proposed model fitted set of observations (Damodar, 2009). The H-L test provide for the Chi-square test of whether or not the model is adequate fit to the data, with the null hypothesis being that the model is of good fit to the data if $\mathrm{p}>0.05$ and the model is poor fit to the data if $\mathrm{p}<0.05$ (Chawla \& Sondhi, 2011). Since the H-L test had a chi square 6.056 and $p$ value of 0.641 , the model passed the goodness of fit test.

\subsection{Data Analysis}

Descriptive and inferential statistics were used to establish the relationship between independent and the dependent variables. Descriptive statistics such as frequencies, percentages, means and standard deviation enabled the 
researcher to meaningfully describe distribution and determine variables' significance. Inferential statistics namely factor analysis; correlation and logit regression were used to establish the relationships between the variables under study and to test the hypotheses (Gujarati, 2003). Preliminary analysis included multicollinearity, sampling adequacy testing and goodness of fit of the model. Binary Logistic Regression analysis was conducted for the hypothesis to determine whether it was statistically supported or not (Cooper \& Schindler, 2011) and it was used to test the likelihood of teachers' retirement preparedness. Logistic regression was used in this study because it was able to determine one or more of the two dependent variable categories by employing binomial probability theory where there are only two values to predict by either belonging to one group (1) or belonging the other group (0) (Field, 2012). Therefore, the study tested whether the independent variables influence the teachers' retirement preparedness. The dependent variable was expected to be either the teachers were prepared for retirement coded as one (1), otherwise zero (0).

To test the hypotheses $(\mathrm{H})$, the equivalent of the $F$ test in the linear regression model was the likelihood ratio statistic which follow the Chi square $\left(\chi^{2}\right)$ distribution with degrees of freedom (df) being equal to the number of explanatory variables excluding the intercept term (Gujarati, 2003). The outcome was interpreted as statistically significant if the $\mathrm{p}$ value was less than or equal to $0.05(\mathrm{p} \leq 0.05)$ and hence reject $\mathrm{H}_{0}$. The logit models were determined by considering the likelihood ratio statistic; the model was okay if $\mathrm{p} \leq 0.05$. More meaningful interpretation was done in terms of odds which were obtained by taking the antilog of the slope coefficients to reveal the number of times the regress and is influenced by the regressor (Gujarati, 2003). The logit model employed to test the statistical significance between the independent and the dependent variables as indicated in models 1 and 2 by computing the overall statistical significance of the predictor variable on the outcome variable (Pampel, 2000).

$$
\begin{aligned}
& \operatorname{Logit}[p]=\ln \left[\frac{p}{1-p}\right]=\beta_{0}+\beta_{1} X_{1}+\ldots+\beta_{n} X_{n} \\
& \text { Logit }[\mathrm{p}]=\beta_{0}+\beta_{1} \mathrm{SO}_{1}+\beta_{2} \mathrm{MO}_{2}+\beta_{3} \mathrm{RC} 3+\mathrm{u}_{\mathrm{i}}
\end{aligned}
$$

Where;

Logit $[\mathrm{p}]$ is the probability of the teachers' preparedness

$\mathrm{B}_{0}$ is the Constant

$\beta_{1}$ to $\beta_{3}$ are the Beta coefficients from the logs of the odds ratio function

$\mathrm{SO}_{1}$ are the social orientation programmes

$\mathrm{MO}_{2}$ are the mentorship opportunities programmes

$\mathrm{RC}_{2}$ are the retirement counselling programmes

$\mathrm{u}_{\mathrm{i}}$ is the error term or random variables

\section{Research Findings}

\subsection{Respondents Characteristics}

The demographic information was about the respondent's gender, marital status, and highest level of education achieved as displayed in Table 1. The response rate was $90.4 \%$ and it formed acceptable basis of drawing the conclusions for this study since Saunders, et al. (2009) argues that a response rate of 50\% is sufficient; response rate of $60 \%$ is good; while response rate of $70 \%$ is very good. 
Table 1. Characteristics of respondents

\begin{tabular}{llrr}
\hline Variable & & Frequency & Percentage \\
\hline Gender & Male & 174 & 57.6 \\
& Female & 128 & 42.4 \\
Marital status & Total & $\mathbf{3 0 2}$ & $\mathbf{1 0 0}$ \\
& Single & 17 & 5.6 \\
& Married & 272 & 90.1 \\
& Divorced & 1 & .3 \\
Highest level of education & Widowed & 12 & 4.0 \\
& Total & $\mathbf{3 0 2}$ & $\mathbf{1 0 0}$ \\
& Diploma & 67 & 22.1 \\
& Degree & 172 & 57.0 \\
& Postgraduate Diploma & 34 & 11.3 \\
& Masters & 29 & 9.6 \\
& Total & $\mathbf{3 0 2}$ & $\mathbf{1 0 0}$ \\
\hline
\end{tabular}

Majority of the respondents were male teachers, $57.6 \%$ (174), married, $90.1 \%$ (272) and were holders of first degree, $57.0 \%$ (172) as the highest level of education. However, 5.6\% (17) were single while 4.0\% (12) were widowed. $22.2 \%$ (67) of the respondents had diploma while 11.3\% (34) had Postgraduate Diploma as the highest level of education. The range of years worked was 29 years while the mean score of the years worked under Teachers Service Commission was 27.72 with a standard deviation of 3.66 .

\subsection{Variables Characteristics}

The three variables of psychosocial programmes namely orientation or embeddedness, mentorship opportunities and retirement counseling were included for the respondents to express opinions on how well they participated in activities that made them well entrenched psychosocially. The characteristics of the variables were as exhibited in Table 2.

Table 2. Characteristics of respondents

\begin{tabular}{lllll}
\hline Variable & No. of Items & Cronbach's Alpha & Mean & S. Dev. \\
\hline Social Orientation or embeddedness & 9 & 0.510 & 3.500 & 1.025 \\
Mentorship opportunities & 5 & 0.690 & 3.354 & 1.160 \\
Retirement counseling & 10 & 0.806 & 2.476 & 1.156 \\
Overall psychosocial programmes & 24 & 0.819 & 3.047 & 1.107 \\
Retirement preparedness & 10 & 0.809 & 3.075 & 1.210 \\
\hline
\end{tabular}

According to Zikmund, Babin, Carr and Griffin (2010), measures of reliability using Cronbach's alpha value range as follows: between 0.5 and 0.6 fair reliability, 0.6 and 0.7 satisfactory, 0.7 and 0.8 good and 0.8 to 1.0 to have very good reliability. For the purpose of this study, Cronbach's alpha value of $\geq 0.5$ was considered the threshold of good reliability. From Table 2, the overall employee's engagement in psychosocial programmes had very good reliability with Cronbach's alpha of 0.819 with a mean score of 3.047 and a standard deviation of 1.107 . The individual variables' reliability was also considered acceptable since it was above 0.5 .

The aggregate mean score for social embeddedness was 3.5 with a standard deviation of 1.02 an indication that the respondents agreed on engaging in activities that promote social orientation but just slightly above the level of indifference. Similarly, seven of the items mean scores (when rounded off) were responded above the level of indifference. However, only four of the activities had a mean score of 4.0 and above even when rounded off with the highest having a standard deviation of 1.32. When rounded off, a mean score of 2.87 revealed that the respondents were not very certain of whether they spent most of their weekend time in school or not. However, a mean score of 1.72 revealed that the respondents did not get bored when they were not in the work place indicating presence of positive social orientation. This implied that the pre-retiree teachers have established and are engaged in activities to spend their time on outside the workplace. This translates to retirees having social support systems and being engaged in utilization of time without suffering boredom during retirement. However, the wide variation in the mean scores across the different items suggests that respondents participate more in some activities (such as extended family meetings) than others (such as discussing about retirement). Similarly, high standard deviation in discussing 
about retirement with relatives $(\mathrm{M}=3.17 ; \mathrm{SD}=1.32)$ indicated that there was great variation in the responses in the item, with some in favour and others against. This concurs with empirical studies that social embeddedness are essential in retirement planning for retirement preparedness (Butters, 2002; Butters, 2004; Shultz \& Henkens, 2010).

To assess the second variable of employee engagement in psychosocial programmes (mentorship opportunities) the respondents were required to answer five items in order to indicate the level at which pre-retiree teachers were a resource to people in their environment. The aggregate mean score for the sub variable was 3.35, slightly above the level of indifference and a standard deviation of 1.16. When asked whether they were regarded as resource by the community, majority $(\mathrm{M}=3.88 ; \mathrm{SD}=0.99)$ were on the affirmative. Moreover, most of the respondents agreed to have been nurturing newly employed teachers $(\mathrm{M}=4.08 ; \mathrm{SD}=0.89)$. However, the respondents were indifferent to invitations by churches, other schools or other fora as a resource to talk to the youth, men and women about education matters $(\mathrm{M}=3$ when rounded off) with high standard deviation (1.33, 1.34 and 1.25 respectively). This suggests that the pre-retiree teachers are mostly occupied with work activities at the precincts of their schools and very little with outside work activities. This reveals that quite a number of pre-retirees lack mentorship opportunities despite being a resource; hence raising questions on the adequacy of engaged in mentorship programmes. This concurs with Itika (2011), that despite mentorship, coaching and advancement opportunities being essential in employee retirement planning, employees seldom get involved as expected.

The third variable to assess employee engagement in psychosocial programmes was retirement counseling with ten items. Since the aggregate mean score was 2.48 (below the indifferent level) and a standard deviation of 1.20 the findings suggests that the pre-retiree teachers were inadequately engaged in retirement counselling. Furthermore, the high standard deviation indicates that the responses had substantial dispersion from along those who agreed and those who disagreed. The study revealed that a significant number of respondents $(\mathrm{M}=2.00 ; \mathrm{SD}=1.17)$ had not been sensitized on the importance of retirement planning in their schools not even once. Worse still, notable number of respondents $(\mathrm{M}=1.9 ; \mathrm{SD}=1.07)$ had not sought retirement counseling from experts. The study further revealed that significant number of respondents do not access information about retirement often through reading literature, listening to media programmes and attending retirement workshops since the items had mean scores lower than the level of indifference and with standard deviations of between 1.01 and 1.74 indicating the dispersion in engagement in the activities amongst respondents.

It was conspicuous that there was no group or individual counselling sessions concerning retirement in the schools of the respondents $(\mathrm{M}=1.57 ; \mathrm{SD}=0.86)$. Similarly, there were no topics earmarked for coverage by a teacher before retirement $(\mathrm{M}=1.69 ; \mathrm{SD}=0.92)$. Comparatively, the findings further reveals that only the items concerning discussions about retirement with spouse, friends and family had a mean score of slightly above the level of indifference. That is, mean scores of 3.63, 3.32 and 3.31 with standard deviations of $1.35,1.24$ and 1.26 respectively. From the foregoing and analysis of the sub variable having an aggregate mean score of 2.48 which was below the level of indifference and standard deviation of 1.20, it implies that pre-retirees' teachers in secondary schools generally have low involvement in retirement counseling activities. This concurs with the findings by Thuku and Ireri (2013) that $67.7 \%$ of public sector employees had not accessed retirement counselling information.

The overall aggregate mean score for the employee engagement in psychosocial programmes was 3.05 and a standard deviation of 1.12. In this respect, it raises uncertainties in pre-retirees' level of engagement in psychosocial programmes. The mean score points out that in terms of the items used, pre-retiree teachers in public secondary schools had not generally engaged in psychosocial programme in their endeavour to plan for separation from the Teachers Service Commission to ensure retirement preparedness. Theoretically, some scholars have presented the need to review the designing of retirement counselling to make it attractive to employees (Willet, 2008). In addition, Wang, et al. (2011) indicated that that $25 \%$ of retirees experienced negative changes in psychological wellbeing during the initial transition stage to retirement.

\subsection{Test of Hypotheses}

A logistic regression was conducted to predict retirement preparedness for 302 pre-retiree teachers using the three indicators of psychosocial programmes as predictors. These were social orientation or embeddedness (SO), mentorship opportunities (MO) and retirement counselling (RC). The authors postulated that the three variables informed the effect of employee psychosocial programmes on retirement preparedness. The results of the logistic regression is presented in Table 3. 
Table 3. Hypotheses testing

\begin{tabular}{lrrrrr}
\hline & $\boldsymbol{\beta}$ & $\mathbf{t}=\boldsymbol{\beta} / \mathbf{S E}$ & Wald & P-Value & Exp(B) \\
\hline Social orientation/embeddedness & .653 & 4.159 & 17.166 & .000 & 1.920 \\
Mentorship opportunities & .463 & 3.430 & 11.828 & .001 & 1.590 \\
Retirement counselling & .433 & 3.115 & 10.259 & .001 & 1.542 \\
Observations (n) & & 302 & & & \\
Nagelkerke R Square & & 0.212 & & .000 & \\
Model Chi - square & $(3 \mathrm{df})$ & 49.691 & & & \\
Classification Rate & & 71.3 & & & \\
-2 Log likelihood & $(8 \mathrm{df})$ & $330.816^{\mathrm{a}}$ & & & \\
Hosmer and Lemeshow Test & & & & & \\
Dependent Variable is Retirement Preparedness & & & & & \\
Note p $\leq 0.05$ & & &
\end{tabular}

After conducting logistic regression exhibited in model 2, the findings were as shown in Table 2. The likelihood ratio, chi square of 49.691 and a $\mathrm{p}$ - value of 0.000 indicates that the model was significantly sound. The Nagelkerke $\mathrm{R}$ Square of 0.212 implied that the model variables identified explained $21.2 \%$ of the variation in the retirement preparedness (outcome) which is a noteworthy relationship between prediction and grouping. The $-2 \log$ likelihood of 330.816 indicated that the model fitted the research data. The prediction sensitivity (percentage correctly predicting that the event occurred) was 182/201 which translated to $90.5 \%$. Conversely, the correctness of prediction that the event did not occur was $67 / 99$ translating to $32.3 \%$. The prediction had an overall success rate of $71.3 \%$.

The positive $\beta$ coefficient of 0.653 for the first predictor variable indicates that increasing the social orientation or embeddedness programmes is associated with increased log odds of retirement preparedness. The Odds ratio expressed as Exp (B) was 1.920 and indicated the effect of the social orientation programmes on the retirement preparedness upon increasing the predictor variable. This implies that, a unit increase in employees' engagement in social orientation or embeddedness activities by the pre-retiree teachers increases the probability of retirement preparedness by $92.0 \%$. From the study findings, the authors opined that employee engagement in social orientation or social embeddedness programmes was statistically significant in predicting whether a pre-retiree teachers were to be prepared for retirement or not. The effect had a Wald of 17.166, $\mathrm{df}=1, \mathrm{p}=0.000$. The authors concluded that there exists a significant positive relationship between pre-retiree teachers' engagement in social orientation or embeddedness programmes and retirement preparedness. Therefore, from the statistical test performed, the first hypothesis was supported and the study therefore accepted $\mathrm{H}_{1}$ that, there is a significant effect of employee's engagement in social orientation programmes on retirement preparedness among teachers' in secondary schools in Kenya since $\beta \neq 0$ and $p-$ value was significant $(P=0.000)$ and less than 0.05 . The study therefore concluded that there is a significant positive relationship between the prevailing social orientation or social embeddedness programmes in pre-retiree teachers of public secondary schools and retirement preparedness in Kenya.

The positive $\beta$ coefficient of 0.463 for the second predictor variable indicate that increasing the mentorship opportunities programmes was associated with increased log odds of retirement preparedness. The Odds ratio expressed as $\operatorname{Exp}(B)$ was 1.590 and indicated the effect of mentorship opportunities programmes on retirement preparedness when the predictor variable is increased. Thus, it means that, a unit increase in employees' engagement in mentorship opportunities programmes by the pre-retiree teachers increases the probability of retirement preparedness by $59.0 \%$. From the study findings, the authors advance that employee engagement in mentorship opportunities programmes was statistically significant in predicting whether a pre-retiree teachers were to be prepared for retirement or not. The effect had a Wald of $11.828, \mathrm{df}=1, \mathrm{p}=0.001$. Therefore, the authors found that there exists a significant positive relationship between pre-retiree teachers' engagement in mentorship opportunities and retirement preparedness. Hence, from the statistical test performed, the second hypothesis was supported and the study therefore accepted $\mathrm{H}_{2}$ that there is a significant effect of employee's engagement in mentorship opportunities programmes on retirement preparedness among teachers' in secondary schools in Kenya since $\beta \neq 0$ and $p-$ value was significant $(p=0.001)$ and less than 0.05 . The study therefore concluded that there is a significant positive relationship between the prevailing mentorship opportunities programmes in pre-retiree teachers of public secondary schools and retirement preparedness in Kenya.

The last predictor variable considered in this study was retirement counselling programmes. The variable had a positive $\beta$ coefficient of 0.433 , exhibiting that, increasing the retirement counselling programmes is associated with 
increased log odds of retirement preparedness. The Odds ratio expressed as $\operatorname{Exp}(\mathrm{B})$ was 1.542 and demonstrated the effect of retirement counselling programmes on retirement preparedness upon increasing the predictor variables. In essence, a unit increase in employee engagement in retirement counselling programmes by the pre-retirees' teachers increased the probability of retirement preparedness by $54.2 \%$. From the findings of this study, the authors were of the opinion that employee engagement in retirement counselling programmes was statistically significant in predicting whether a pre-retiree teachers were to be prepared for retirement or not. The effect had a Wald of 10.259, $\mathrm{df}=1, \mathrm{p}=0.001$. Therefore, the study found a significant positive relationship between engagement in retirement counselling and retirement preparedness. Consequently, the study accepted the third hypothesis $\left(\mathrm{H}_{3}\right)$ that there is a significant effect of employee's engagement in retirement counseling programmes on retirement preparedness among teachers' in secondary schools in Kenya since $\beta \neq 0$ and $p-$ value was significant $(p=0.003)$ and less than 0.05 . The study therefore concluded that there is a significant positive relationship between the prevailing retirement counseling programmes in pre-retiree teachers of public secondary schools and retirement preparedness in Kenya.

\section{Discussions and Implications}

The psychosocial programmes were conceptualized to constitute the social orientation or social embeddedness, mentorship opportunities and retirement counseling. The aggregate mean score for social embeddedness was 3.5 with a standard deviation of 1.02 an indication that the respondents agreed on engaging in activities that promote social orientation but just slightly above the level of indifference. The relatively high standard deviation indicated that there was great variation in the responses. The findings reveal that pre-retiree teachers engage in social activities outside the work place such as going to church, attending family meetings and being part of community gatherings such as funerals and weddings. Surprisingly, participation of pre-retiree secondary school teachers in activities that created room for social interactions outside the work place was not a conscious planning for retirement. It appears that the teachers usually spend most of their time in school and are "cut off" from the diversified social life outside the circle of fellow teachers. The foregoing risk the pre-retirees to the danger of social exclusion once retired. This concurs with empirical studies that social embeddedness is essential in retirement planning for retirement preparedness (Butters, 2002; Butters, 2004; Shultz \& Henkens, 2010).

In assessing employee engagement in mentorship opportunities, the aggregate mean score for the variable was 3.35, slightly above the level of indifference and a standard deviation of 1.16. The high standard deviation indicates variations in responses on the level of involvement in mentorship programmes. The study revealed that pre-retiree teachers found themselves mentoring the newly employed teachers posted in their schools especially those teaching in their departments. Rarely did the pre-retiree teachers participate in forums to speak to church youths in organized seminars or to students in other schools during guidance and counseling sessions. Notably, the utilization of time was a great concern especially during the long December holiday for teachers who were not engaged in marking national examinations. The foregoing suggests that the pre-retiree teachers were mostly pre-occupied with school work activities at the precincts of their schools and very little with outside work activities. This reveals that quite a number of pre-retirees lack mentorship opportunities despite being a resource; hence raising questions on the adequacy of engaged in mentorship programmes. This concurs with Itika (2011), that despite mentorship, coaching and advancement opportunities being essential in employee retirement planning, employees seldom get involved as expected.

The third variable to assess employee engagement in psychosocial programmes was retirement counseling whose aggregate mean score was 2.48 far below the indifferent level, and a standard deviation of 1.20. The findings suggest that the pre-retiree teachers were inadequately engaged in retirement counselling with the responses showing substantial dispersion from along those who agreed and those who disagreed as revealed by the high standard deviation. The study revealed that there lacked active participation on retirement counseling or education by the pre-retiree teachers. Strangely, pre-retiree teachers had seldom sought voluntarily retirement counseling in addition to schools not organizing such forums. In addition, the literature read with content on retirement planning and preparation was negligible. Surprisingly, the pre-retired teachers had heard about the need for retirement preparedness in media programmes inadvertently. These findings imply that pre-retiree teachers in secondary schools generally have low involvement in retirement counseling activities. The study findings concur with the findings by Thuku and Ireri (2013) that $67.7 \%$ of public sector employees had not accessed retirement counselling information. This is further supported by the findings of Potocnik and Sonnentag (2013) that, psychosocial planning programmes include engagement in non-work activities such as volunteer work, community and religious groups and such activities are significantly related to increased psychosocial well-being in retirement. Since retirement counseling enlighten on retirement information, inadequate engagement in retirement counseling doubtlessly contribute to in sufficient retirement preparedness. As such, availing retirement counselling to pre-retirees is imperative in 
empowering with psychosocial planning options before separation from employer organization for the post retirement life.

The findings from the hypotheses support empirical findings of Wang and Hesketh (2012) that retiree's participation in psychological and social activities such as family support systems positively affects retirement preparedness because they provide companionship. This was further in concurrence to the results of Chan, Gustafsson and Liddle (2015) that effective retirement planning programmes enhance psychosocial resources of an individual and hence improve adaptation in retirement transition. Indeed, the empirical findings that engagement in psychosocial programmes had a significant positive effect on retirement preparedness are particularly important in assisting individual employees to plan for separation from employer organization and subsequent life in retirement. Pre-retiree teachers' engagement in psychosocial programmes makes individuals to be prepared for retirement. Psychosocial programmes are therefore indispensable because they safeguard retirees from suffering stigmatization through loss of social status and social identity in the society, and loss of friendship resulting to social exclusion. Such programmes involved elements that include retirement counseling, social embeddedness and community outreach to guarantee successful retirement life.

The pre-retirees' engagement in psychosocial programmes geared towards social orientation, mentorship opportunities and retirement counseling provide an up-to-date knowledge to support theorists of role transition, life course perspective and theory of planned behaviour (Wang, Henkens \& van Solinge, 2011; Wang et al., 2011). The study therefore contributes to the body of knowledge by extending the understanding of the theoretical underpinnings in the study of separation planning for retirement preparedness namely role theory, continuity theory, life course perspective and the theory of planned behaviour. Since most of the literature on retirement preparedness has to a large extent considered retirement planning from a narrow perspective of financial retirement planning of retirees (Dalirazar, Vornovytskyy \& Hedengren 2010; Berry, 2010; Shultz \& Wang, 2011). The findings of this study provide empirical information on psychosocial retirement planning and extend the frontier of knowledge to other variables that are imperative in employee separation planning and post retirement life preparedness.

The empirical findings of the study have implications to the policy makers and practitioners for improving the likelihood of successful retirement preparedness by employees when still in employment through informed separation planning through engagement in psychosocial programmes for retirement. The social pillar of Kenya Vision 2030 should be enlarged to also focus on a holistic approach in retirement preparedness psychosocially. The government of Kenya should put in place a national strategy and partner with other institutions such as the County government to ensure employee engage in appropriate psychosocial activities as enablers of senior citizens to age gracefully. It is worth acknowledging the efforts being made by the Retirement Benefit Authority in empowering Kenyans to financially plan for separation to retirement life, however, effort should be made to also focus on the other four facets such psychological and social dimensions of retirement preparedness.

\section{Conclusions}

From the research findings on the hypotheses, the study concluded that the psychological and social activities (psychosocial programmes) have a significant positive effect on retirement preparedness in the life of pre-retirees' teachers in public secondary schools. Moreover, the psychosocial programmes (social embeddedness, mentorship opportunities and retirement counseling) are imperative and instrumental in reinforcing the advancements by role and continuity theorists that life ought to continue without major disruptions such as loss of social identity, friendship and social exclusion. However, the study established that pre-retiree teachers have not adequately engaged in psychosocial programmes as pre-planning strategy in readiness for retirement life. The research suggests that employees should actively engage in activities or programmes that increase the capacity for psychological and social wellbeing in post-retirement life. This conclusion forms a significant step in understanding employee separation planning by appealing to employees to deliberately endeavor to engage in psychosocial programmes when still in the work place since it is a neglected aspect. In any case, the truth is out there that the employers in essence mind about service delivery even when they pledge to care for the employee. The employee therefore should clearly think and plan for his/her life after mandatory retirement age (separation from employer). The findings extend the theoretical insights by providing empirical evidence that psychosocial programmes are part of other elements that constitute separation planning.

\section{Limitations and Recommendations for Further Study}

Although the study made conclusions based on the evidence obtained from the survey data, it is important to highlight areas that may limit the extent of generalization and applicability of the findings. The study relied on subjective data obtained as opinions since the data on retirement planning was self-reported in the questionnaire. 
There might have been some over or under reporting of the levels of separation planning and retirement preparedness. Thus, the absence of objective data to some extent limits the extent of generalization of the conclusions made. In addition, the study considered only three variables to constitute psychosocial programmes leaving others that may be of importance. The study was conducted in the educational sector only, specifically in public secondary schools in Kirinyaga and Murang'a Counties in Kenya. Secondary school teachers being only one professional with its uniqueness and strict code of service, to a small extent limits the level of generalizations. It would be interesting to see how similar or different would other sectors showcase.

Further research may be conducted to address some or all of the cited limitations. Future studies could therefore be extended to other industries (such as banking, manufacturing, technological, construction among others) in Kenya, in order to enrich the knowledge of employee separation planning and retirement preparedness in terms of psychosocial engagements for retirement preparedness. In addition, future research may consider enlarging the variables to constitute psychosocial programmes and enlarge the methodology by employing longitudinal studies and other methods of data collection

\section{References}

Beehr, T.A., \& Bennett, M.M. (2007). Examining retirement from a multi-level perspective. In Shultz, K.S., \& Adams, G.A. (Eds.), Aging and Work in the 21 st Century (pp. 277-302). New York: Psychology Press.

Berry, C. (2010, June). The future of Retirement. The International Longevity Centre-UK (ILCUK) discussion paper.

Butters, J. (2002). Managing the mental and emotional aspects of retirement. Leadership in Health Services, 15(4), 6-11. https://doi.org/10.1108/13660750210452152

Butters, J. (2004). Managing finances for a fulfilled Canadian retirement. Leadership in Health Services, 17(1), 12-18. https://doi.org/10.1108/13660750410515871

Chan, M.L., Gustafsson, L., \& Liddle, J. (2015). An intervention to support professional driver retirement transition: Results of a pilot study for older taxi drivers in Singapore. British Journal of Occupational Therapy, 21, 1-10.

Chauvet, G. (2015). Coupling Methods for Multistage Sampling. The Annals of Statistics, 43(6), 2484-2506. https://doi.org/10.1214/15-AOS1348

Chawla, D., \& Sondhi, N. (2011). Research Methodology: Concepts and Cases. New Delhi: Vikas Publishing House Pvt Ltd.

Cooper, D.R., \& Schindler, P.S. (2011). Business research methods (11th ed). New Delhi-India: MacGraw-Hill Publishing Co. Ltd.

Dalirazar, N., Vornovytskyy, M.S., \& Hedengren, D. (2010). Can Americans Afford to Retire?. Washington, DC: U.S. Census Bureau.

Davies, E., \& Jenkins, A. (2013). The work to retirement transition of academic staff: attitudes and experiences. Employee Relations, 35(3), 322-338. https://doi.org/10.1108/01425451311320503

Donaldson, T., Earl, J.K., \& Muratore, A.M. (2010). Extending the integrated model of retirement adjustment: Incorporating mastery and retirement planning retrieval. Journal of Vocational Behaviour, 77, 279-289. https://doi.org/10.1016/j.jvb.2010.03.003

Dorfman, L.T., \& Douglas, K. (2005). Leisure and the retired professor: Occupation matters. Educational Gerontology, 31, 343-361. https://doi.org/10.1080/03601270590921645

Ekerdt, D.J. (2004). Born to retire: The foreshortened lifecourse. The Gerontologist, 43, 3-9. https://doi.org/10.1093/geront/44.1.3

Elder, G.H., \& Johnson, M.K. (2003). The life course and aging: challenges, lessons, and new directions. In Settersten, R.A.Jr (Ed.), Invitation to the Life Course: Toward New Understandings of Later Life (pp. 49-81). Baywood, Amityville.

Feldman, D.C., \& Beehr, T.A. (2011, April). A Three-Phase Model of Retirement Decision Making. American Psychologist, 66(3), 193-203.

Field, A.P. (2012). Discovering Statistics using R. New Delhi: Sage Publications.

Fox, N., Hunn, A., \& Mathers, N. (2009). Sampling and Sample Size Calculations. The National Institute for Health Research, Research Design Service, Yorkshire.

Gujarati, D.N. (2003). Basic Econometrics (4th ed.). Mc Graw Hill, New York.

Hesketh, B., Griffin, B., Dawis, R., \& Bayl-Smith, P. (2014). Extensions to the Dynamic Aspects of the Retirement Transition and Adjustment Framework (RTAF): Adjustment Behaviours, Work Styles, and Identity. Work, Aging 
and Retirement, Oxford University Press.

Hooyman, N., \& Kiyak, H. (2000). Social gerontology: A multidisciplinary perspective. Boston: Allyn and Bacon Press.

Itika, J.S. (2011). Fundamentals of human resource management: Emerging experiences from Africa. African studies center, African Public Administration and Management series.

Kim, J., \& Moen, P. (2001). Is retirement good or bad for subjective well-being?. Current Directions in Psychological Science, 10(3), 83-86. https://doi.org/10.1111/1467-8721.00121

Kim, J., Kwon, J., \& Anderson, E.A. (2005). Factors Related to Retirement Confidence: Retirement Preparation and Workplace Financial Education. Financial Counseling and Planning, 16(2).

Mariappanadar, S. (2012). Do retirement anxieties determine bridge employment preference? A study among pre-retirees in the Australian construction industry. Emerald Group Publishing Limited, 42(2), 176-204.

McVittie, C., \& Goodall, K. (2012). The ever-changing meanings of retirement. American Psychologist, 67(1), 75-76. https://doi.org/10.1037/a0026259

Muratore, A.M., \& Earl, J.K. (2010). Predicting retirement preparation through the design of a new measure. Australian Psychologist, 45(2), 98-111. https://doi.org/10.1080/00050060903524471

Pampel, F.C. (2000). Logistic Regression: A primer. Thousand Oaks, CA: Sage Publications. https://doi.org/10.4135/9781412984805

Phua, V.C., \& McNally, J.W. (2008). Men planning for retirement: Changing meaning of preretirement planning. Journal of Applied Gerontology, 27, 588-608. https://doi.org/10.1177/0733464808321885

Potocnik, K., \& Sonnentag, S. (2013). A longitudinal study of wellbeing in older workers and retirees: The role of engaging in different types of activity. Journal of Occupational and Organizational Psychology, 86, $497-521$.

Quick, H., \& Moen, P. (1998). Gender, employment, and retirement quality: A life course approach to the different experiences of men and women. Journal of Occupational Health Psychology, 3(1), 44-64. https://doi.org/10.1037/1076-8998.3.1.44

Sargent, L.D., Bataille, C.D., Vough, H.C., \& Lee, M.D. (2011). Metaphors for retirement: Unshackled from schedules. Journal of Vocational Behavior, 79(2), 315-324. https://doi.org/10.1016/j.jvb.2011.03.002

Sekaran, U., \& Bougie, R. (2009). Research methods for business (5th ed.). Wiley publication.

Shultz, K., \& Wang, M. (2011). Psychological perspectives on the changing nature of retirement. American Psychologist, 66(3), 170-179. https://doi.org/10.1037/a0022411

Shultz, K.S., \& Henkens, K. (2010). Introduction to the changing nature of retirement: an international perspective. International Journal of Manpower, 31(3), 265-270. https://doi.org/10.1108/01437721011050567

Shultz, K.S., \& Wang, M. (2007). The influence of specific health conditions on retirement decisions. International Journal of Aging and Human Development, 65, 149-161. https://doi.org/10.2190/AG.65.2.c

Thuku, P.W., \& Ireri, A.M. (2013). Relationship between Access to Retirement Information and Retirement Preparation among Prospective Retirees in Nyeri County, Kenya. Open Journal of Social Science Research, 1-6. https://doi.org/10.12966/ojssr.04.01.2013

Van Solinge, H.V., \& Henkens, K. (2008). Adjustment to and satisfaction with retirement: Two of a kind?. Psychology and Aging, 23, 422-434. https://doi.org/10.1037/0882-7974.23.2.422

Wang, M. (2007). Profiling Retirees in the Retirement Transition and Adjustment Process: Examining the Longitudinal Change Patterns of Retirees. Psychological Well-Being, Journal of Applied Psychology, 92(2), 455-474. https://doi.org/10.1037/0021-9010.92.2.455

Wang, M., \& Hesketh, B. (2012). Achieving Well-Being in Retirement: Recommendations from 20 Years of Research. Society for Industrial and Organizational Psychology, Inc. SIOP White Paper Series.

Wang, M., \& Shultz, K.S. (2010). Employee retirement: a review and recommendations for future investigation. Journal of Management, 36(1), 172-206. https://doi.org/10.1177/0149206309347957

Wang, M., Henkens, K., \& Van Solinge, H. (2011). Retirement Adjustment: A Review of Theoretical and Empirical Advancements. American Psychologist. https://doi.org/10.1037/a0022414

World Health Organization. (2012). World Health Statistics. Geneva, Switzerland: Author.

Yamane, T. (1967). Statistics: An Introduction analysis (2nd ed.). New York: Harper and Row.

Zhan, Y., Wang, M., Liu, S., \& Shultz, K.S. (2009). Bridge employment and retirees' health: A Longitudinal Investigation. Journal of Occupational Health Psychology, 14(4), 374-389. 